\title{
Ecosystem modelling provides clues to understanding ecological tipping points
}

\author{
Éva E. Plagányi ${ }^{1, *}$, Nick Ellis ${ }^{2}$, Laura K. Blamey ${ }^{3}$, Elisabetta B. Morello ${ }^{2}$, \\ Ana Norman-Lopez ${ }^{1}$, William Robinson ${ }^{4}$, Miriana Sporcic ${ }^{1}$, Hugh Sweatman ${ }^{5}$ \\ ${ }^{1}$ Climate Adaptation and Wealth from Oceans Flagship, CSIRO, PO Box 2583, Brisbane, QLD 4001, Australia \\ ${ }^{2}$ Wealth from Oceans Flagship, CSIRO, PO Box 2583, Brisbane, QLD 4001, Australia \\ ${ }^{3}$ Marine Research (MA-RE) Institute, University of Cape Town, Private Bag X3, Rondebosch 7701, South Africa \\ ${ }^{4}$ Marine Resource Assessment and Management, Department of Mathematics and Applied Mathematics, \\ University of Cape Town, Private Bag X3, Rondebosch 7701, South Africa \\ ${ }^{5}$ Australian Institute of Marine Science, PMB3, Townsville MC, QLD 4810, Australia
}

\begin{abstract}
Ecological thresholds, associated with abrupt changes in the state and organisation of ecosystems, challenge both scientists and managers. Adaptive response to such changes, and planning for their occurrence, requires an understanding of the underlying drivers and system responses as well as appropriate monitoring. In addition to field studies, modelling can advance our ability to anticipate or deal with such major ecosystem shifts. Here, we used an existing multispecies model with smooth continuous functions that were modified to include thresholds representing 3 alternative scenarios of predator responses when prey numbers drop below a critical threshold: (I) no threshold-like response; (II) an abrupt decrease in breeding success by $90 \%$, and (III) an abrupt halving of adult survival. Second, we analysed field observations from 3 independent marine case studies (abalone, starfish, penguins) for evidence of abrupt non-linear responses of predators to changes in abundance of principal prey. Third, we compared the model output with empirical results and tested (using both a statistical method and by fitting multispecies models) the 3 alternative response scenarios. With this approach, we found evidence for nonlinear changes in population parameters (such as survival rate) of predators as prey numbers declined below critical thresholds. As an example of the potential for this approach to inform management, we found that abundances of a range of marine predators become more variable as prey numbers decline, which may be a useful indicator that a system is approaching a tipping point.
\end{abstract}

KEY WORDS: Abrupt change - Ecological thresholds · Adaptive management - Trophodynamics · Intermediate complexity model $\cdot$ Non-linear responses

\section{INTRODUCTION}

Shifts in ecosystem state, particularly unexpected ecological changes, represent major challenges for management. To prevent dramatic state changes, it is necessary to understand the underlying drivers as well as system responses and to monitor and respond adaptively, either through early intervention management measures or by strategically planning for changes ahead. Ecological thresholds are defined as the point where there is an abrupt change in an ecosystem quality, property or phenomenon, or where large ecosystem responses result from relatively small changes in an environmental driver (Groffman et al. 2006). There is currently limited biological understanding with which to accurately parameterise threshold responses, but these responses are both plausible and important 
(Hughes 1994, Scheffer et al. 2001, Bakun \& Weeks 2006).

Ecological thresholds have been observed empirically and studied theoretically, particularly in the context of multiple stable states (May 1977, Scheffer 1990, Scheffer \& Carpenter 2003). For example, Casini et al. (2009) identified an ecological threshold (measured in units of zooplanktivorous fish abundance) separating 2 ecosystem configurations in the Baltic Sea. Early theoretical notions about thresholds and breakpoints showed that continuous changes in a control variable (such as harvesting rates or predation rates) can lead to discontinuous effects (such as collapse in fisheries or sudden outbreaks of insect pests) (May 1977). There are multiple examples of systems that seem to shift between alternative stable states rather than responding smoothly and continuously to changing conditions (McCook 1999, Norstrom et al. 2009).

Key disturbances, both natural and anthropogenic, initiate non-linear changes in ecosystem state. Theory suggests that key disturbances can (1) be abrupt events themselves, such as cyclones (Fig. 1A), (2) induce change because a critical threshold in an environmental variable is crossed (e.g. nutrient loading, salinity change) (Fig. 1B), or (3) destabilise a previously stable ecosystem because its resilience is reduced resulting in hysteresis and the presence of alternative stable states (Fig. 1C) (Scheffer \& Car- penter 2003, Blamey et al. 2014). The time it takes for a disturbance pulse to propagate through an ecosystem can hinder the ability to detect the shifting state because of the need to monitor at an appropriate time-scale. Shorter-lived lower trophic-level organisms will typically respond more rapidly and sometimes more dramatically. Basic population dynamics theory predicts there will be a lag before longer-lived higher trophic level species start to decline in abundance. Possible outcomes for impacted species whose numbers have declined include recovery (Fig. 1D), remaining at reduced levels (Fig. 1E) or change to a new stable state (Fig. 1F) with no possibility of returning to the previous state even if the causal drivers subside.

Nonlinearity of responses confounds our ability to model and predict system responses; most ecosystem models assume smooth changes in system variables and responses. Moreover, multiple interacting drivers typically act together to push a system over the tipping point. The need to understand threshold concepts becomes even more urgent under changing climate where new environmental drivers are added to existing anthropogenic stressors such as fishing and pollution. The growing adoption of adaptive management principles allows management to be adjusted in response to monitoring data to maintain a path towards management goals and targets. Several researchers have recognised the need for early warn-
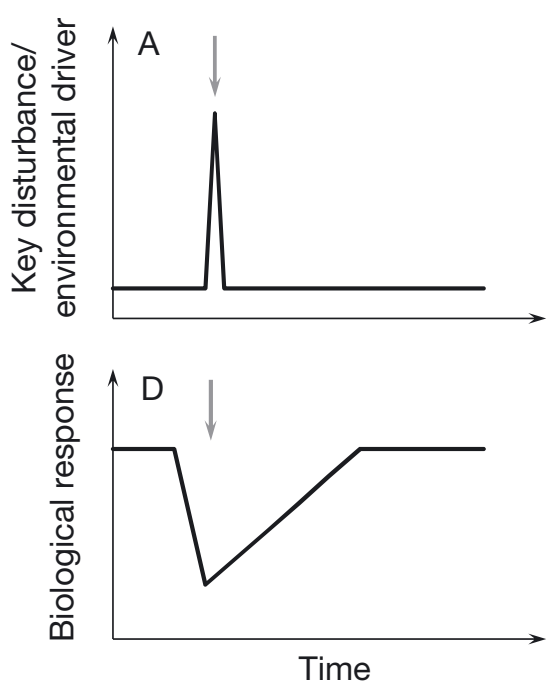
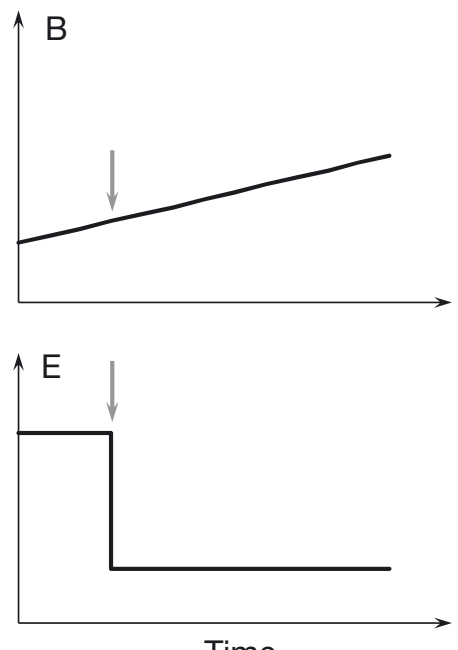

Time
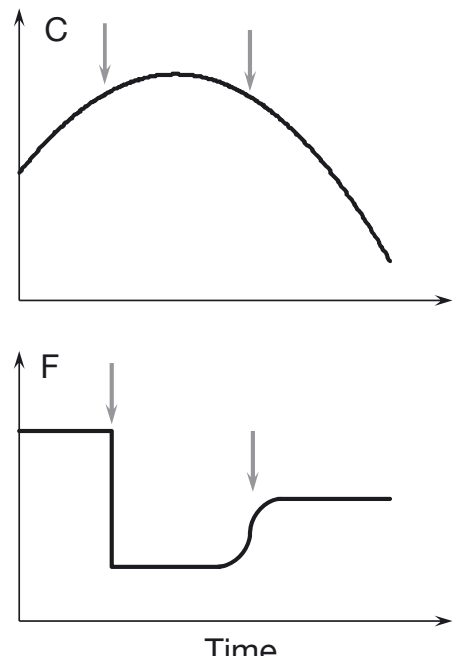

Time

Fig. 1. Schematic time series showing the (A-C) types of disturbance and (D-F) corresponding change in ecosystem state/biological response. Disturbances can be (A) abrupt events resulting in pulse responses which eventually recover (D); critical threshold responses (B) resulting in reduced levels of the indicator of ecosystem state once a critical threshold in the disturbance is reached $(\mathrm{E})$; or very small changes in an environmental driver $(\mathrm{C})$ that causes a biological response and the low resilience of the system prevents it from returning to its original state resulting in hysteresis and the presence of alternative stable states (F). The change in (D-F) in turn mediates a similar change (with some time lag added) in a dependent species such as a predator. Grey arrows show correspondence between the (A-C) disturbance time series and (D-F) biological response time series, indicating where the thresholds are (modified from Andersen et al. 2009, Bestelmeyer et al. 2011) 
ing signals to identify approaching tipping points, while pointing to the substantial theoretical and empirical challenges, such as distinguishing early warning behaviours from noise (Carpenter \& Brock 2006, Boettiger \& Hastings 2012, Boettiger et al. 2013).

In this paper, we first used an existing predator-prey model (Plagányi \& Butterworth 2012, Plagányi 2013) and modified smooth continuous functions to include thresholds describing the response of predators to changes in prey abundance below a critical threshold. Secondly, we used field observations from 3 case studies to examine the occurrence of non-linear and abrupt responses of predators to changes in prey. Thirdly, we compared the model output with the empirical changes in predator numbers and tested (with both a simple statistical method and fitted multispecies models) whether a particular underlying model was statistically justified. In particular, we develop a simple indicator that reflects whether a system is approaching a tipping point, and we propose a method involving quantifying increased variability in predator changes as prey are more depleted. We focus on an abrupt change in a system and how it comes about without also considering the potential reversibility of the change or shift. Moreover, we restricted our focus to individual species' responses in the marine environment, and to a limited number of examples rather than a comprehensive overview, in order to keep the analysis tractable. Finally, we explore how this information might be used to inform management.

Three sets of observations of linked changes in predator-prey populations were available for analysis from these studies: abalone-urchin (Case A), crownof-thorns starfish (COTS)-coral (Case B), and penguin-sardine (Case C) (Fig. 2). In Case A, following an eastward shift in the West Coast rock lobster Jasus lalandii along South Africa's southwest-
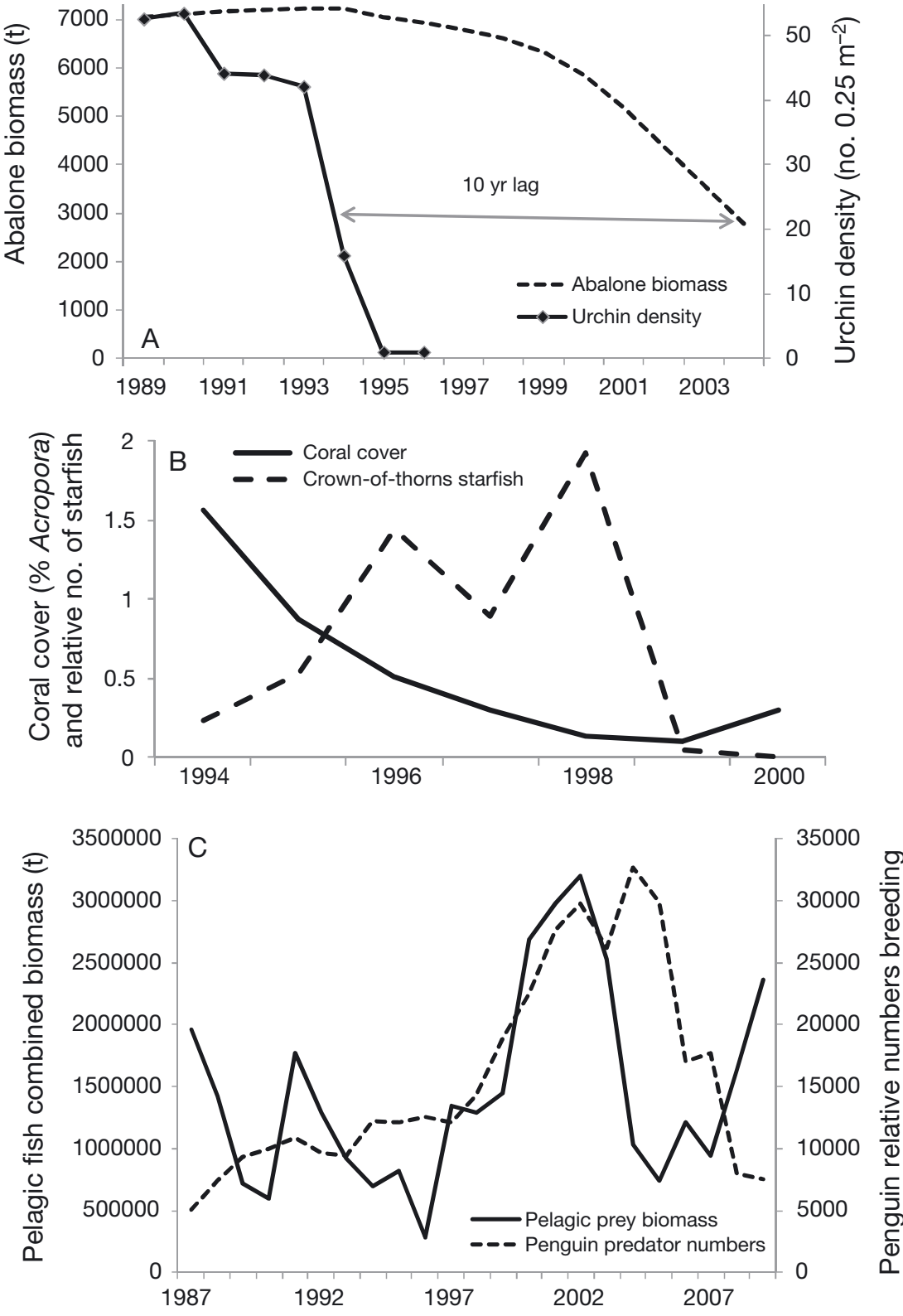

Fig. 2. (A) Observed abrupt decrease in the density (no. per $0.25 \mathrm{~m}^{2}$ ) of urchins Parechinus angulosus (from Tarr et al. 1996) at a south-western coastal site in South Africa, shown together with the lagged decline in the spawning biomass (t) of co-occurring abalone Haliotis midae (Plagányi \& Butterworth 2010, Blamey et al. 2013). The 10 yr delay before similar rapid declines are observed in the abalone population is due to the absence of urchins, resulting in a decline in juvenile numbers of this long-lived species. (B) Observed rapid increase and decrease in crown-of-thorns starfish Acanthaster planci (no. of starfish tow ${ }^{-1}$ ) shown together with percentage cover of fast-growing corals of the genus Acropora at Lizard Island, Great Barrier Reef (GBR); a density of starfish $>0.22$ starfish tow $^{-1}$ is enough to cause coral decline on most GBR reefs (incipient outbreaks; Sweatman et al. 2008). (C) Observed decrease in the pelagic fish biomass (shown as the combined sardine Sardinops sagax and anchovy Engraulis encrasicolus - from Coetzee et al. 2008) in the vicinity of South African west coast penguin colonies followed by an abrupt decrease in the regional numbers of breeding African penguins Spheniscus demersus (from Underhill et al. 2006) 
ern coast (Cockcroft et al. 2008), urchin populations Parechinus angulosus declined abruptly (Tarr et al. 1996, Mayfield \& Branch 2000). Juvenile abalone Haliotis midae are protected by urchin spines and benefit from an enhanced food supply due to urchins retaining drift kelp (Day \& Branch 2000 a,b). Consequently, they declined in synchrony with the urchins. The abrupt urchin decline and associated abalone recruitment in the affected area resulted in a decline in the abalone spawning biomass but with an approximately $10 \mathrm{yr}$ delay before the decline became detectable (Fig. 2A) (Blamey et al. 2010, 2013, Plagányi \& Butterworth 2010).

Second (Case B), we consider an outbreak of the COTS on Lizard Island in Australia's Great Barrier Reef (GBR), which we refer to as the COTS-coral case study. We used data collected annually in an extensive GBR long-term monitoring program (Sweatman et al. 2000) and finer-scale data from 4 COTS-affected reefs at Lizard Island sampled at 2 to 5 mo intervals from October 1996 to January 1999 (Pratchett 2005, 2010). The COTS abundance includes only larger emergent individuals, as the smaller cryptic individuals are not easily counted. Predation by the COTS results in a substantial decline in the local (percentage) coral cover, and COTS numbers decline abruptly after 3 yr (Fig. 2B). Predator and prey are thus apparently linked by a negative feedback loop whereby the COTS deplete their coral prey to the extent that they cause their own demise (De'ath \& Moran 1998).

Third (Case C), the biomass of both anchovy Engraulis encrasicolus and sardine Sardinops sagax peaked concurrently around 2002 in the southern Benguela (de Moor et al. 2008, 2011), but sardine populations along South Africa's west coast declined thereafter due to an eastward shift in their distribution (Coetzee et al. 2008). The eastward shifts in sardine and West Coast rock lobster coincided with cooling of inshore waters that took place on the south coast during the 1980s/1990s (Roy et al. 2007, Coetzee et al. 2008, Rouault et al. 2009, 2010). The decline in the abundance of pelagic fish, the dominant prey of African penguins Spheniscus demersus, was followed by a steep decline in penguin breeding numbers (with a time-lag effect, given 3-4 yr maturation time) at 2 of the major colonies on the west coast (Cury et al. 2000, Crawford et al. 2006) (Fig. 2C).

For each of these case studies, we use modelling and statistical analyses to distinguish whether the underlying response of a predator to its principal prey (or a species that it depends on, e.g. for shelter) decreasing below a critical threshold is most likely due to an impact on breeding success or survival of the predators. Our definition of a critical threshold follows Lenton (2011, p 202): "it is 'the tipping point' beyond which a qualitative change occurs" (immediately or later). Threshold foraging behaviour is common in higher vertebrates which rely on aggregated prey and have high metabolic demands (e.g. Piatt \& Methven 1992). Hence, for species with tight predator-prey dependencies, their nutritional intake may be too low to sustain breeding, or even their own survival, once prey density drops below a threshold level. Analogously, in the abalone example above, once urchin density reaches a tipping point, there are insufficient alternative shelters (such as rock crevices) available for juveniles to shelter under, and hence the balance of the population is vulnerable to increased predation (Blamey et al. 2013). We show that residual plots (based on available annual monitoring data for a species) that show increasing variability of the rate of change (or absolute size of the residuals) may provide an indicator that the system is approaching a tipping point.

\section{METHODS}

\section{Modelling threshold responses}

The impact and plausibility of alternative abrupt threshold-like interaction responses is explored using a spatial multi-species operating model (SMOM) of krill-predator-fishery dynamics (Plagányi \& Butterworth 2012, see also the Supplement at www.int-res. com/articles/suppl/m512p099_supp.pdf for a detailed model description). The model can be used to focus on the question of this paper and has the following features. Krill Euphausia superba is the sole prey of 4 predator groups, namely penguins, seals, fish and whales. The dependence of predators on prey is modelled using a survival and reproductive success factor that is a function of the available biomass of prey and acts as a multiplier to the juvenile recruitment parameters, namely the reproduction and/or the juvenile survival rate. Thus, the predator-prey interaction term links predator breeding success directly with prey abundance, avoiding the need for an explicit consumption-related term. A single parameter controls the level of prey abundance (relative to the single- or multi-species carrying capacity) below which there is an appreciable negative impact on predator breeding success. Parameter values from previous model applications infer increasing sensitivity to decreasing prey (krill) abundance from 
whales (least sensitive) to seals, fish, and penguins (most sensitive) (Plagányi \& Butterworth 2012, Plagányi 2013). A steady state analysis of SMOM (detailed in the Supplement) suggests that seals are able to maintain high population levels even at relatively low prey levels, but penguins are unable to sustain themselves once prey drops below around $25 \%$ of the prey carrying capacity (Fig. S1), i.e. there are no equilibrium solutions possible for penguins at lower prey levels as the populations are predicted to decline rather than stabilize (unless demographic parameters change or they are able to switch to alternative prey). It has long been recognized (Holling 1973) that there are domains in a phase plane where the predator or prey is unable to persist and that adding lags to the dynamics alters the results of stability analyses. Dynamic SMOM simulations enabled us to explore the net effect of periodic but non-persistent substantial decreases in prey abundance.

A prey abundance perturbation, resulting in an abrupt decrease in krill biomass down to $14 \%$ of the initial level, is used to investigate the impact on dependent predator populations (Fig. 3). We defined a critical threshold prey density as the prey level below which predators are severely impacted. The critical threshold was set (in the absence of further information) at $20 \%$ of the average carrying capacity because this is a commonly used limit reference level in fisheries management (e.g. Australian Government 2007). Scenario I did not include a thresholdlike response. Two forms of threshold response were explored as follows. In Scenario II, if prey abundance fell below the threshold, the breeding success multiplier was assumed to immediately drop to $10 \%$ of its value. In Scenario III, the predator response to prey abundance dropping below the threshold level was for adult survival to decrease by half.

\section{Comparing model results and empirical examples}

The 3 examples presented in Fig. 2 are revisited in the context of findings from this study's simulations. Changes in populations in the field are most readily measured by changes in the numbers of the mature (adult) population, with rapid decreases or increases in population numbers indicating corresponding trends in an overall population. The rate of change (or derivative) in absolute or relative population numbers is a key indicator to identify abrupt changes
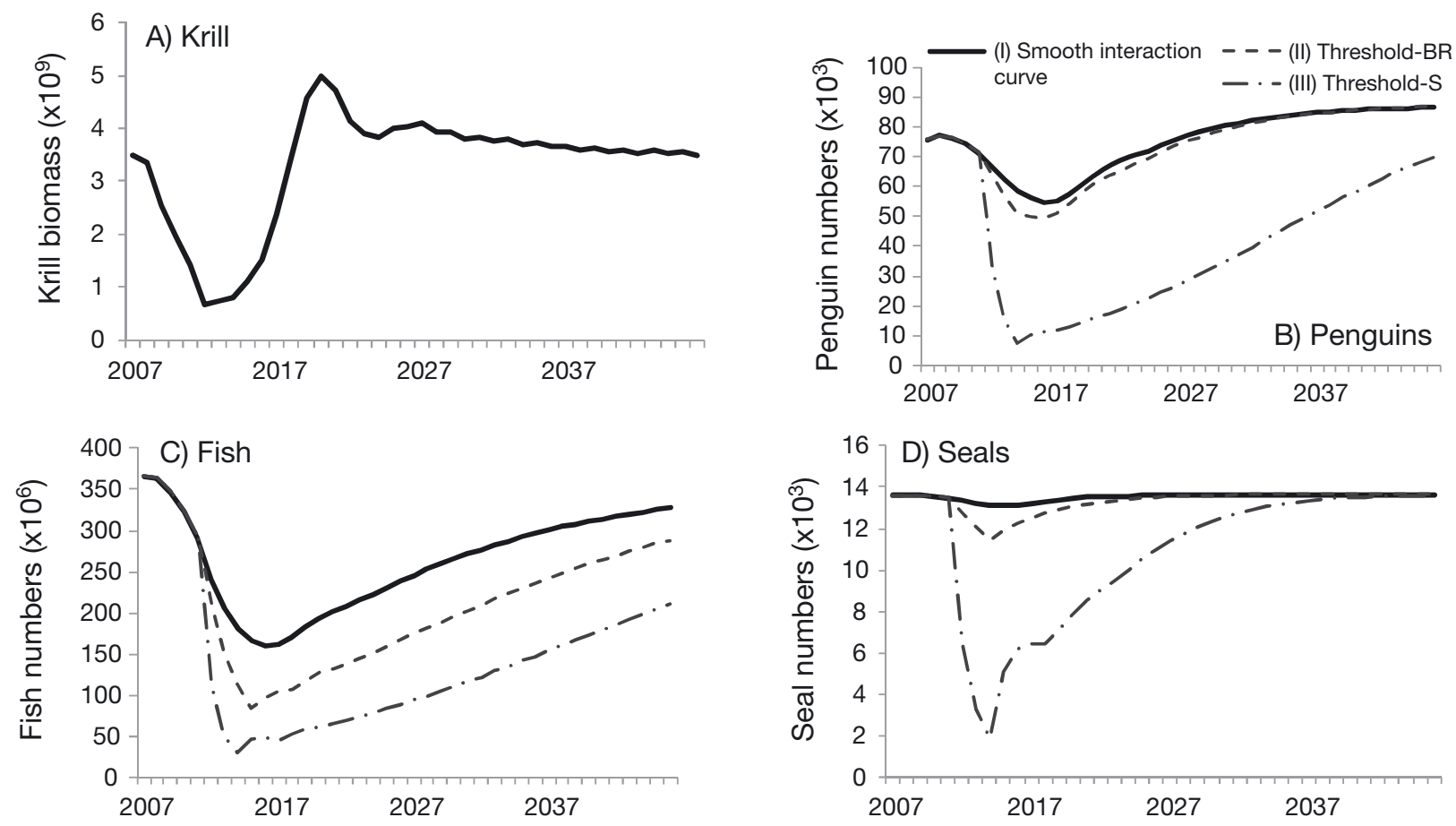

Fig. 3. Model-predicted population trajectories for (B) penguins, (C) fish and (D) seals in the Drake Passage West region of the Antarctic Peninsula, in response to a negative perturbation in (A) krill (prey) abundance. Solid line: Scenario I response, which assumes a smooth underlying relationship between breeding success and krill abundance; dashed line: Scenario II response, which assumes a threshold-type relationship whereby breeding success (BR) drops markedly below the threshold krill level; dash-dot line: Scenario III response, which assumes that adult survival (S) is primarily impacted 
in population status. To replicate a straightforward method that could be applied to field observations, we computed the proportional rate of change $\delta n_{i}$ simply as the difference between the current number of predator individuals in year $i, N_{i}$, and previous year's population estimate $N_{i-1}$ as a proportion of the previous year's estimate:

$$
\delta n_{i}=\frac{N_{i}-N_{i-1}}{N_{i-1}}
$$

Next we plotted $\delta n_{i}$ as a function of the relative depletion $p_{i}$ of a key prey species (or other species the predator depends on) (Fig. 4). Relative depletion was calculated as the current (prey) abundance relative to the maximum observed value (a proxy for pristine abundance). The annual change in the modelled numbers of penguins, fish and seals under Scenarios I-III (Fig. S2) were computed and compared with the corresponding plots (Fig. 4) derived from the observed changes in abalone, starfish and penguin numbers as shown in Fig. 2.

In order to identify which of the modelled patterns (I-III) were most similar to the observed patterns, we characterized the modelled patterns by the degree to which variation of $\delta n_{i}$ increased with decreasing $p_{i}$. This can be understood by reference to Fig. 5, which shows the continuous trajectories of $\frac{\mathrm{d}}{\mathrm{d} t} \log N$, the instantaneous relative rate of change of penguin abundance against relative krill abundance, computed by running the simulated models on a very fine time step. All 3 models start at the 'first year' point and are identical up to the 'abrupt change', where they diverge. Each trajectory then follows a sweeping clockwise curve back near to the starting point. The contrast in vertical amplitude of these curves at low prey abundance relative to that at high prey abundance is the distinguishing trait that we shall try to detect.

With the continuous curves in Fig. 5 it is obvious that Scenario III has the largest variation and Scenario I the smallest variation. However, for annually sampled data $\left(\delta n_{i}\right)$, the observations will be much sparser and estimation of the variation is required, which in turn requires an estimate of the mean about which the variation is spread. One possibility is to gather the data into bins of $p_{i}$ and measure the contrast in standard deviation across bins. However, this requires a choice of bin width: if it is too narrow, the bins will contain only a single point; if it is too wide, we cannot distinguish low and high prey abundance. Instead of discrete binning, we used a continuous method to measure the contrast in variation. We first computed a smooth approximation to $\delta n_{i}$ as a func- tion of $p_{i}$ using local regression or loess (Cleveland et al. 1992), as implemented in the $\mathrm{R}$ development environment ( $\mathrm{R}$ Core Team 2013). This is a procedure that estimates the mean of $\delta n_{i}$ at each value of $p_{i}$ using least-squares regression of $\delta n_{i}$ on a quadratic function of $p_{i}$ within a local window. The optimal width of this window, which is analogous to the bin size of the binning approach, is found using leaveone-out cross-validation. Given this smoothed mean, the residuals $r_{i}$ quantify the variation. Finally, we defined the contrast in variation as the magnitude of the slope of the regression line of $\left|r_{i}\right|$ on $p_{i}$ (Fig. 6). This number is the characterizing trait for each modelled pattern.

Where possible, we then calculated this trait for the observed data: it was applied to the patterns describing the penguin-pelagic prey (Fig. 4G) and penguin-sardine (Fig. 4H) relationships (Fig. S3 in the Supplement). The observed pattern was then informally ascribed to one of the mechanisms (Scenarios I-III) by comparison with the value of the slopes from the modelled data; it is reasonable to suppose the slopes are comparable, given that the change quantity is dimensionless. Empirical data were too sparse to apply this method for the other cases (Fig. 4A-F).

\section{Using model selection to select between Scenarios I-III for the three case studies}

For each of our 3 case studies, abalone-urchin (Case A), COTS-coral (Case B), and penguinsardine (Case C), we tested which of Scenarios I-III best explained the data: Scenario I with no thresholdlike response; Scenario II such that if prey abundance fell below a low threshold value (default value $20 \%$ of the average carrying capacity or maximum observed population level), the breeding success multiplier immediately dropped, with default decrease down to $10 \%$ of its original value; or Scenario III, such that the predator response to the prey level dropping below the threshold was for adult survival to decrease, with a default decrease of $50 \%$.

We fitted existing statistical multispecies models to the data (Tables S1-S6 in the Supplement) and obtained the minimum of the total negative loglikelihood function (see Table S5 for equations of log-ikelihood contributions and associated residual standard deviation) using the quasi-Newton minimisation algorithm within AD Model Builder (Fournier et al. 2012). The Hessian-based estimated standard errors were used to assess the precision of the various parameter estimates. We used Akaike's information 


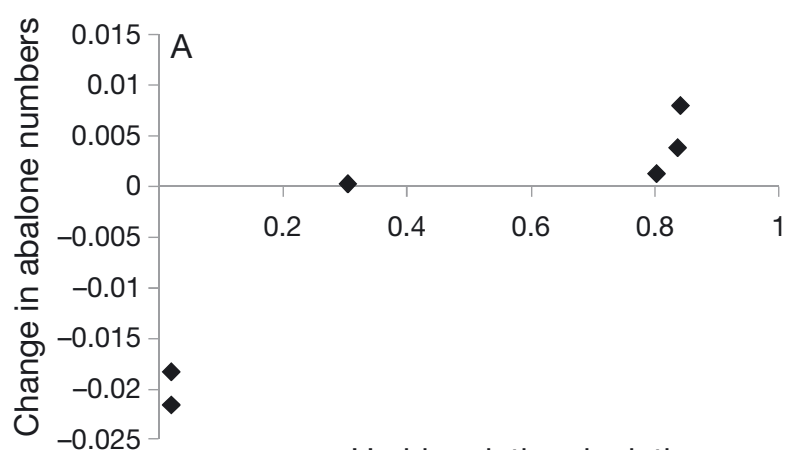

Urchin relative depletion
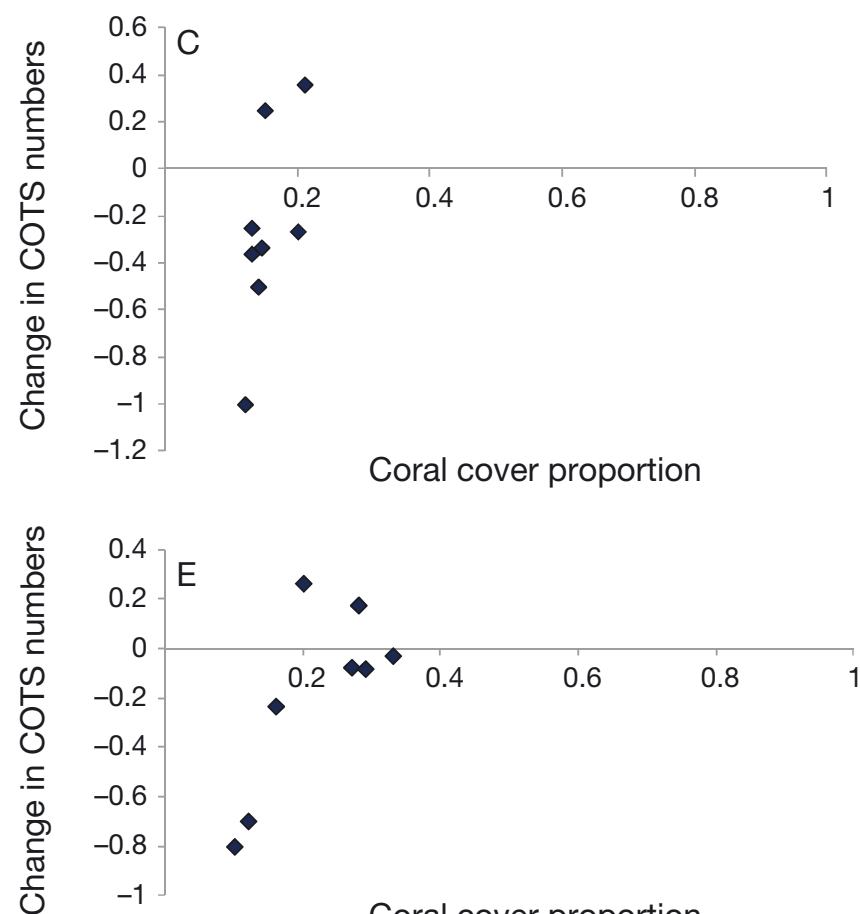

Coral cover proportion

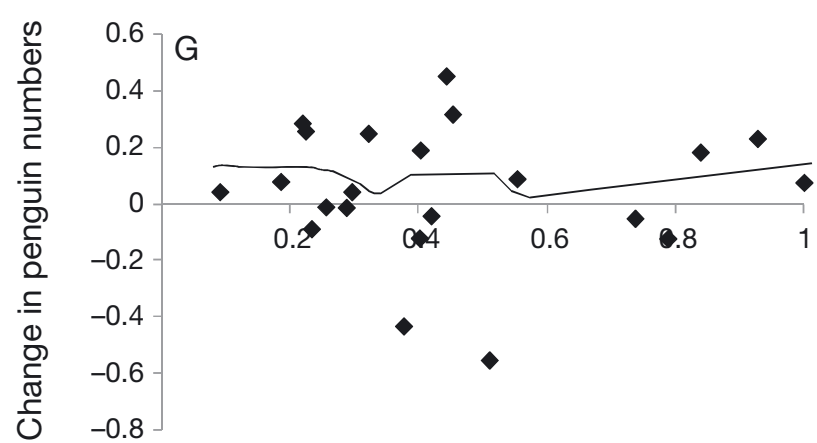

Pelagic prey relative depletion

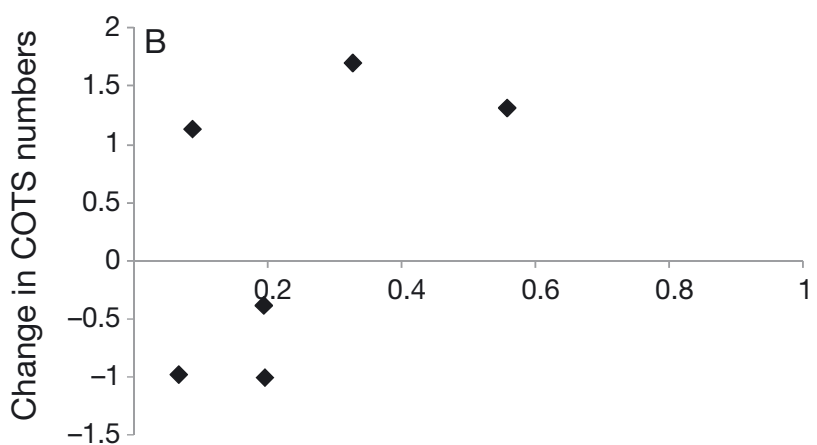

Coral cover relative reduction

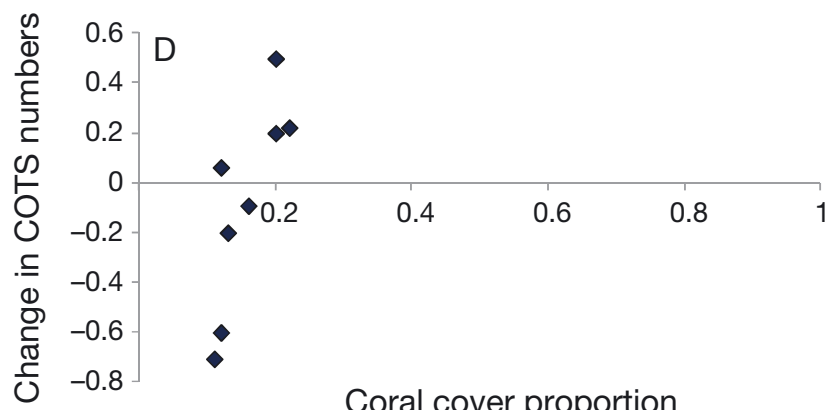

Coral cover proportion
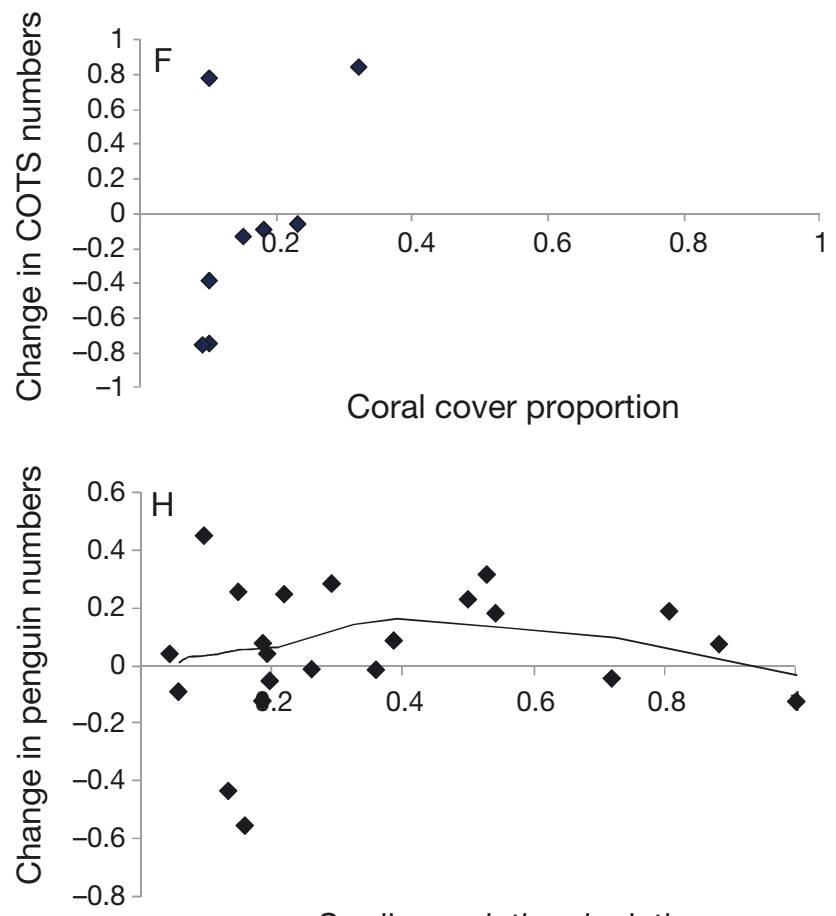

Sardines relative depletion

Fig. 4. Observed predator/dependent species rates of change as a function of the relative depletion of a key prey (or other key co-occurring species): (A) abalone and their dependency on urchins, (B) crown-of-thorns starfish (COTS) which predate on fast-growing coral at Lizard Island, Great Barrier Reef (based on long-term monitoring program annual data) and (C-F) from ca. 4 mo periodic surveys at individual reefs (Pratchett 2005, 2010), namely (C) North Reef, (D) Lizard Head, (E) Casuarina, and (F) Corner Beach. African penguins as a function of (G) pelagic prey (combined anchovy and sardine) depletion level or $(\mathrm{H})$ sardine depletion level only. Relative depletion was calculated as the current (prey) abundance relative to the maximum observed value (used as a proxy for pristine abundance) 


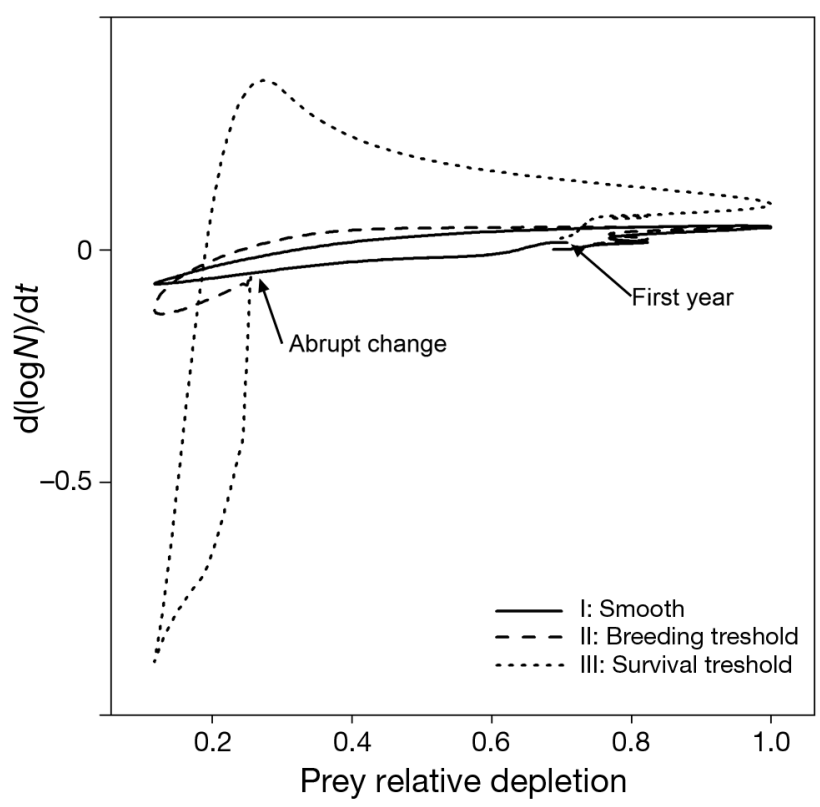

Fig. 5. Continuous trajectories of instantaneous relative rate of change of penguin abundance $\left(\frac{\mathrm{d}}{\mathrm{d} t} \log N\right)$ against relative prey depletion (ratio of abundance to maximum abundance) for each of the 3 scenarios (Scenarios I-III) criterion (AIC) to select between model versions under the 3 scenarios. For Scenarios II and III, we first ran the models using the default decrease percentages $(10$ or $50 \%)$, then re-ran the model to estimate the decrease percentage and determine if that resulted in an improved fit to the observations.

For Case A, we used the abalone-urchin multispecies model as described in Blamey et al. (2013). The urchin-abalone interaction was incorporated in the form of juvenile abalone survival relative to urchin densities, where abalone survival decreases exponentially below a specified urchin-density threshold ( 0.3 of the carrying capacity of urchins, equivalent to ca. 30 urchins $\mathrm{m}^{-2}$; Mayfield \& Branch 2000). Hence, Scenario III was implemented by assuming that survival drops immediately to some percentage of its base value when urchin density drops below the threshold value. Scenario II was implemented by adding to the recruitment equation a multiplier that decreased from 1 to a set percentage whenever the urchin density dropped below the threshold value. For the COTS-coral case study (Case B), we used the multispecies model of Morello et al. (2014,

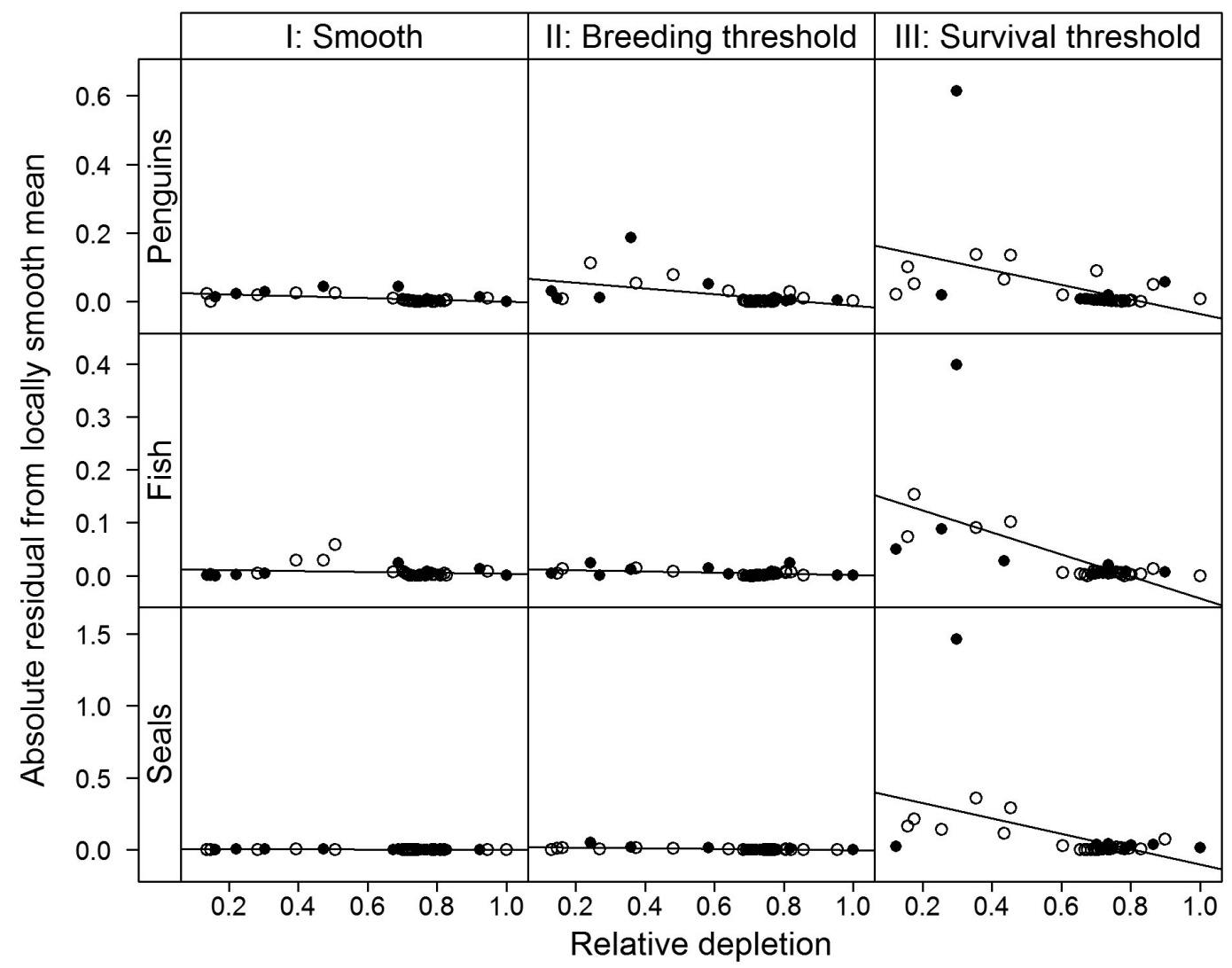

Fig. 6. Absolute loess residuals versus relative depletion using model output shown in Fig. S2 in the Supplement at www.intres.com/articles/suppl/m012p099_supp.pdf. (•) Positive residuals, (O) negative residuals. Slope estimates are provided in Table 1 
this Theme Section). Lastly, we used a simplified (non-spatial non-seasonal) version of SMOM to model the penguin-sardine case study (Case C) (see Tables S4-S5 for parameter values and equations, which are mostly based on Robinson 2013).

\section{RESULTS}

\section{Modelling threshold responses}

Penguins, fish and seals are all relatively longlived, and the Antarctic ecosystem model predicted that populations would decrease but then bounce back again in response to a decreasing perturbation in krill abundance (Fig. 3). Given the greater sensitivity of penguins and fish to changes in prey abundance compared with seals (Fig. S4) the former 2 groups showed a greater response to krill dropping below the threshold. There was a noticeable difference between the non-threshold-like response (Scenario I) and the Scenario II threshold response for fish only. However, there was a markedly more severe response in all cases under Scenario III.

\section{Comparing model results and empirical examples}

As prey density is reduced in the model, there is a steeper inter-annual change in modelled numbers of penguins, fish and seals from Scenario I through to Scenario III (Fig. S2). This is expected, and it is precisely these rates of change that form the basis of many differential equation-based models. The point of the current exercise is to explore whether there are predictable patterns that might emerge in response to underlying processes such as threshold-like responses. Inversely, comparing these patterns with empirical observations from different systems might yield clues as to the underlying mechanisms responsible for changes in that ecosystem; hence, the model patterns in Fig. S2 are to be compared to the empirically derived plots in Fig. 4. Note that the empirical examples in Fig. 2 are independent of the models used in this study.

There was no clear pattern in change in African penguin numbers versus relative depletion of pelagic fish (anchovy and sardine) in the region (Fig. 4G). By contrast, a more striking pattern was evident from changes in penguin numbers versus sardine relative depletion alone (Fig. 4H) that again resembled the model Scenario III in which survival drops beyond a threshold value of sardine biomass. This is noteworthy because although anchovy comprise a larger pro- portion of the diet of African penguins in the study area, sardines have a higher energetic value and hence may be a disproportionately more important contributor to the survival of adult penguins.

When fitting a loess-smoothed curve and regressing the absolute residuals against depletion using the model output, the slope was significant in all cases except Scenario I (no-threshold; Table 1). The slope was also substantially more negative $(<-0.2)$ for the survival-related threshold case (Scenario III) compared with the breeding threshold Scenario II, which in turn was more negative than the no-threshold Scenario I, which had values closer to zero (Table 1, Fig. 6). This suggests that a simple scale of absolute residuals may be a diagnostic for distinguishing the models. Similarly, as expected, this method also distinguished the empirical penguin-pelagic fish from the penguin-sardine relationship. As is evident from the loesssmoothed curve (Fig. 4G) and absolute residual plots (Fig. S3, left) in the Supplement, for the penguinpelagic fish relationship, the variability (about the smoothed curve) is roughly uniform across the range of depletion values. In contrast, for the penguinsardine relationship (Figs $4 \mathrm{H} \& \mathrm{~S} 3$, right) the variability is higher at low depletion than at high depletion; i.e. there is an increase in the variance as the penguin population starts to decline substantially (see also Fig. 5). The trend in the absolute residuals differs, because for the first case it is somewhat dome-shaped, whereas for the second it descends from high to low (Fig. S3). The straight line slopes (the heuristic trait) are therefore roughly zero and non-zero, respectively, and the negative slope was significant for the latter but not the former (Table 1, Fig. S3). Also the slope value around -0.2 may point towards the survival-related threshold Scenario III.

Table 1. Estimated slope of absolute loess residuals versus relative depletion using model output (see Fig. S2 in the Supplement; www.int-res.com/articles/suppl/m512p099_ suppl.pdf) and empirical data (see Fig. 4G,H). ${ }^{*}$ Significant $(p<0.05)$ slope estimate. For the empirical cases, the value is placed in the column having the closest modelled values

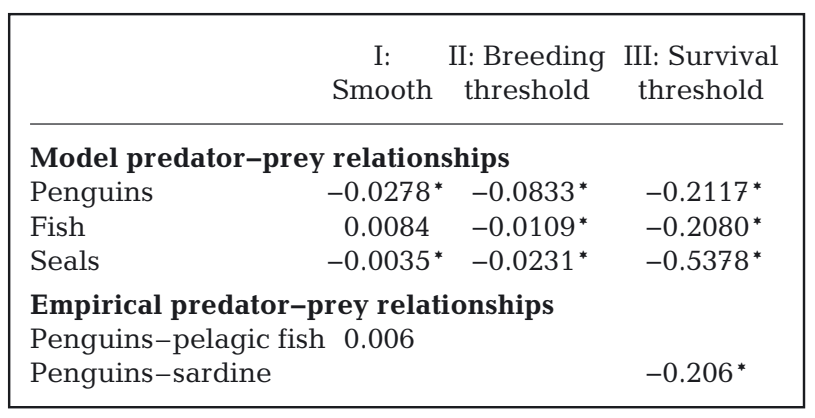




\section{Using AIC to select among Scenarios I-III for the three case studies}

For all 3 case studies, the preferred model (based on minimum AIC) was the version with Scenario III implemented and with the survival rate decrease (in response to sub-threshold prey levels) estimated in the fitting process (Table 2; see also Table S6). The survival decrease proportions were well estimated (small standard error relative to estimated value) for the abalone and African penguin models, but not for the COTS example (Table 2). The values of 33, 82 and $9 \%$ of the adult survival for abalone, penguins and COTS, respectively, were statistically significantly different to the default value of $50 \%$ used in the illustrative Antarctic simulations, suggesting that the decrease in survival in response to a decrease in prey is case-specific. In the COTS model under Scenario III, the natural mortality estimate decreased (or conversely, survival estimate increased) compared with Scenario I, and collectively the lower 'average' natural mortality and sudden steep increase when prey drops sub-threshold was considered the more likely model. Similarly, in the penguin-sardine example, the Scenario III model estimated a higher survival rate than Scenario I in order to fit an increase in the population, which was then followed by a very rapid downturn. Scenario II models generally did not result in overall improvements in the fit and the breeding success decrease parameters were difficult to estimate (Table 2). For the penguin-sardine model, the best-fit estimate of the latter parameter was 0 , whereas for the abalone-urchin example it was 1 (effectively suggesting no effect). A number of other sensitivities were also run and attempts were made to estimate the 2 decrease parameters simultaneously, as well as the critical (threshold) prey level (i.e. values other than $20 \%$ ), but, of the models that converged, none were preferred statistically, and hence these results are not shown. The plots in Fig. 4 are fairly consistent in suggesting that the critical threshold prey level may typically be slightly below $20 \%$ of the maximum prey level (the default setting), but the available data were too sparse to reliably estimate this parameter.

\section{DISCUSSION}

\section{Modelling predators' responses to low prey availability}

Model results clearly showed the relationship between the assumed sensitivity of each predator to changes in prey abundance versus the resultant impact of prey decreases on predator population trajectories. It was difficult to distinguish between a nonthreshold-like response (Scenario I) and a threshold response (Scenario II) affecting the breeding success of a predator. This result is consistent with the notion that fairly long-lived predators are able to integrate out the longer-term effects of periodic prey shortages and recruitment variability (Boyd et al. 1995), and hence the simulations here do not provide sufficient

Table 2. Comparison of negative log-likelihood (-lnL) and Akaike's information criterion (AIC) model scores for the 3 case studies and for each of the 3 alternative scenarios. Scenario I: a smooth continuous relationship between predator performance and prey abundance; Scenario II: a threshold response whereby predator breeding success decreases abruptly below a critical prey threshold level, with the extent of decrease either (a) fixed or (b) estimated as shown; and Scenario III: a threshold response whereby adult predator survival rate decreases abruptly below a critical prey threshold level, with the extent of decrease either (a) fixed or (b) estimated as shown. The lowest AIC scores are shown in bold. COTS: crown-of-thorns starfish

\begin{tabular}{|c|c|c|c|c|c|}
\hline $\begin{array}{l}\text { Case study / } \\
\text { Model }\end{array}$ & $\begin{array}{l}\text { (I) No } \\
\text { threshold }\end{array}$ & $\begin{array}{l}\text { (IIa) Breeding } \\
\text { threshold fixed }\end{array}$ & $\begin{array}{l}\text { (IIb) Breeding } \\
\text { threshold est. }\end{array}$ & $\begin{array}{l}\text { (IIIa) Survival } \\
\text { threshold fixed }\end{array}$ & $\begin{array}{l}\text { (IIIb) Survival } \\
\text { threshold est. }\end{array}$ \\
\hline (A) Abalone-urchin model & & 0.1 & 1.00 & 0.5 & 0.33 \\
\hline No. parameters estimated & 6 & 6 & 7 & 6 & 7 \\
\hline$-\operatorname{lnL}($ total) & -156.716 & -151.439 & -158.498 & -151.511 & -168.660 \\
\hline $\mathrm{AIC}$ & -301.432 & -290.878 & -302.996 & -291.022 & -323.32 \\
\hline (B) COTS-coral model & & 0.1 & 0.12 & 0.5 & 0.09 \\
\hline No. parameters estimated & 7 & 7 & 8 & 7 & 8 \\
\hline$-\operatorname{lnL}($ total) & -19.704 & -15.831 & -20.943 & -24.793 & -28.215 \\
\hline $\mathrm{AIC}$ & -25.408 & -17.662 & -25.886 & -35.586 & -40.430 \\
\hline (C) Penguin-sardine model & & 0.1 & 0.00 & 0.5 & 0.82 \\
\hline No. parameters estimated & 2 & 2 & 3 & 2 & 3 \\
\hline$-\operatorname{lnL}($ total) & -19.209 & -19.209 & -20.583 & 0.862 & -30.535 \\
\hline AIC & -34.418 & -34.418 & -35.165 & 5.723 & -55.069 \\
\hline
\end{tabular}


evidence for this as a key mechanism underlying abrupt ecosystem change. In contrast, our model predicted that threshold-like changes in predator survival (and particularly adult survival) in response to prey shortages (Scenario III) have sustained and severe impacts on population trajectories. These results were obtained assuming a lesser decrease in survival ( $50 \%$ decrease) compared to that in breeding success (90\% decrease) when prey abundance drops below the critical threshold level. Model results therefore suggest that abrupt changes in populations and ecosystem shifts can more readily be ascribed to a threshold-like response of adult survival to changing conditions rather than to breeding success or a recruitment collapse. Adult mortality removes not only the adults but also their reproductive potential.

Interestingly, in the penguin-pelagic fish example, changes in adult survival are thought to be the primary cause of the rapid decline in penguins (Robinson 2013, and see comment by D. Butterworth et al. ${ }^{\mathbf{1}}$ ). In the abalone-urchin example, consumption of urchins by lobsters is thought to be responsible for the abrupt decrease in urchins (Blamey \& Branch 2012, Blamey et al. 2013). However, this in turn impacts the survival (rather than recruitment per se) of juvenile abalone, inducing a similarly rapid decline in juvenile abalone. There is a $10 \mathrm{yr}$ lag before the impacts are manifest on the overall abalone biomass given that the lifespan of Haliotis midae is in excess of 15 yr. For COTS, the exact mechanism causing the decline at the end of the outbreak cycle at a particular reef is unclear but is most likely due to reduced survival resulting from a food shortage and/or disease (Zann et al. 1990, De'ath \& Moran 1998, Pratchett 2005).

\section{Empirical comparisons: ecosystem-scale responses}

It was noteworthy that the change in abalone numbers as a function of the relative depletion of urchins most closely resembled the model scenario in which survival drops below a threshold value even though the adult abalone population trajectory appears to be relatively smooth (and computing the relative change shows that the derivative is greatest some $8 \mathrm{yr}$ after

\footnotetext{
1BButterworth D, Brandao A, de Moor CL, Robinson W. Claim by Pichegru et al. that marine no-take zone benefits penguins remains premature. Biol Lett eLetter, February 9, 2011. http://rsbl.royalsocietypublishing.org/content/6/4/498/ reply\#roybiolett_el_82
}

the urchin collapse). Thus, even though there is a considerable lag (being the years before juveniles are large enough to grow into spawning adults) before the effect of the threshold-like reduction in urchins (and hence abalone recruits) is observable in the adult population, annual changes in the adult population provide a clue that the decreasing trend may be due to a threshold-like response. In this case it is possible to verify the result because the data are from a wellstudied system in which a regime shift has occurred (Blamey et al. 2012). However, this is not typically the case, as in many fisheries (or population studies) indices of abundance such as catch-per-unit-effort data are only available for the fishable or mature population, and there would likely not be comparable timeseries on juvenile recruitment or trends in a co-occurring species (such as the urchin in this example).

COTS are known to be specialist coral feeders targeting particular corals such as Acropora spp. (De'ath \& Moran 1998, Pratchett 2007). At the end of an outbreak, lack of food induces a decrease in COTS condition and may also lead to increased susceptibility to disease (Zann et al. 1990, Pratchett 2005). Irrespective of the specific reason for the COTS population decline, ultimately it is adult survival, rather than breeding success, that appears to be responsible. Moreover, further support for the inferred link between the threshold-like response and adult survival is as follows: (1) COTS outbreaks have been correctly predicted to occur, on average, every $15 \mathrm{yr}$ as a function of coral recovery times (Seymour \& Bradbury 1992, Fabricius et al. 2010), and (2) successive outbreaks have been correctly predicted to be less intense owing to progressive declines in coral cover (Seymour \& Bradbury 1992, 1999).

In our statistical analyses we looked for non-constant variance (a heteroskedastic response as a function of depletion) because we were trying to detect a non-linear response in order to distinguish between the 3 scenarios. The rapidly descending and ascending parts of the curves contribute to the variation in change as a function of depletion. This variation seems to increase from Scenario I to III. The penguin-sardine biomass relationship most closely resembled the model Scenario III, and this was also supported by the trait analysis finding of a significant negative slope $(-0.2)$ of the absolute residuals against depletion. This suggests sardines may be a disproportionately more important contributor to the survival of adult penguins. The decline in the sardine population in the vicinity of the main west coast penguin breeding colonies is attributed to an environmentally mediated eastward shift in the distribution 
of sardine (Roy et al. 2007, Coetzee et al. 2008). During the same period, the number of penguin breeding pairs at these colonies decreased by $75 \%$ (Crawford et al. 2006). A lack of available food is thought to be the main cause of higher adult mortality and lower breeding success in recent years. The results obtained in this study are consistent with the findings of Robinson (2013). attributing the penguin decline to a decline in adult survival, but it is noteworthy that the simple analysis presented here points to a dominant mechanism possibly being an abrupt decrease in adult penguin survival in response to a decline in sardines. Robinson (2013) found that penguin survival starts to decrease substantially when sardine biomass in November (west of Cape Agulhas) drops below $25 \%$ of the maximum observed. Based on a global empirical analysis, Cury et al. (2011) identified a threshold prey abundance of approximately onethird of the maximum level as the level below which seabird breeding success declines.

Our analyses also highlight the challenges in obtaining sufficient empirical data to test statistically for smooth versus abrupt underlying trophodynamic relationships. Absolute residual plots are a common diagnostic in model fitting when you want to test the assumption of constant variance. Fitting a straight line to the absolute residuals is the simplest way of detecting non-constant variance. Our residual regression test shows some promise as a diagnostic for distinguishing between scenarios, with slope values around -0.2 likely pointing towards an abrupt survival-related threshold influencing dynamics and greater magnitude of slope suggesting greater threshold response. More data or greater resolution in existing series (e.g. monthly values rather than annual values) will permit better discrimination between alternative threshold types.

Models allow 'experimental' investigations that are difficult or impossible in the field. The patterns that emerge can be compared with equivalent plots of empirical data from unrelated systems, and an inverse deduction can be used to reveal clues as to the underlying mechanisms responsible for the population changes. Models used for this purpose should ideally have been tested first using suitable data, be tractable, and of intermediate complexity (Blamey et al. 2013, Plagányi et al. 2014). In addition, flexible interaction representation forms such as that used in SMOM are necessary to explore non-linear abrupt responses to external disturbances as well as posited threshold-type responses of a predator to changes as they propagate through an ecosystem.

\section{Summary of results and implications}

Equilibrium concepts are largely theoretical constructs, since real ecosystems are challenged with change almost constantly and perhaps increasingly so under the current anthropogenically mediated climate change. However, to avoid surprisingly large shifts in ecosystems, it is generally accepted that there is a need to maintain resilience (Hughes 1994, Folke et al. 2004, Hughes et al. 2007), for example by conserving biodiversity and avoiding excessive depletion of individual, and particularly key, species.

We presented 3 examples of fairly dramatic changes observed in kelp forest, coral reef and open ocean ecosystems. In the abalone-urchin case (Case A), the lobster 'invasion' triggered an alternative stable state, making a return to pre-invasion urchin and abalone conditions unlikely (Blamey et al. 2013). In the penguin-pelagic fish case (Case B), the predicted outcome is currently being studied. The COTS-coral case (Case C) is similar to outbreaks described globally for COTS, with intensity and frequency of outbreaks as well as recovery trajectories differing among coral reefs (Seymour \& Bradbury 1992, 1999, Pratchett 2007). In the modelled Antarctic system, as predicted from the functional relationships, the predators all recovered (albeit at different rates), when krill biomass increased. However, if penguins exhibit depensatory dynamics as has been hypothesized by some (Lynch et al. 2012, Watters et al. 2013), then the modelled recoveries may be overoptimistic.

The field observations and modelling analyses presented here suggest that rapid declines in the abundance of these species are most likely caused by changes in survival (assuming no emigration). Wolf \& Mangel (2008) highlight the need to test multiple hypotheses simultaneously when investigating population declines, although a relatively large amount of data, and preferably spatially disaggregated data, may be needed to distinguish between alternative hypotheses. Our approach is similar to their recommended ecological detection approach in which different models are confronted with data to determine which proposed mechanisms, singly or in combination, best explain the observed data. We used our alternative models to test for a nonlinear change in either breeding success or survival as the predominant effect, as there was insufficient information to assume a nonlinear change in both.

Our results suggest that there may be more value in focusing monitoring of longer-lived species on changes in survival (e.g. using tag-recapture methods) than breeding success (e.g. nest counts) as an 
indication that dramatic state changes are occurring. Plots of the annual rate of change of a dependent species as a function of the relative depletion of the key species it relies on may provide clues that fundamental changes, rather than normal fluctuations, are occurring in system state. Moreover, our analyses suggest that the absolute size of the residuals may be a simple and useful diagnostic for distinguishing threshold types, and hence providing an early warning that a system is approaching a tipping point.

Our study corroborates previous findings that increasing variance is a leading statistical early warning signal of regime shifts and may be present in a variety of systems, including ecological, physical, social and financial (Carpenter et al. 2008, Scheffer et al. 2009). Previous studies have shown an increase in variance in daily chlorophyll time series from a lake field experiment (Carpenter et al. 2008), in freshwater cladoceran populations (Drake \& Griffen 2010), laboratory yeast populations (Dai et al. 2012), in climate data (Lenton 2011), and in catch data from collapsing fisheries (Litzow et al. 2013). Additional empirical tests of these indicators are needed, particularly in a management context (Litzow et al. 2013). Our study is the first to use both modelling and empirical observations from a range of marine populations (starfish, abalone, penguins) and, in a management context, to show that increasing variance in population monitoring data may similarly signal a forthcoming abrupt decline. Moreover, we demonstrate that the predominant mechanism causing the decline may be a nonlinear decrease in survival (e.g. we estimated an $18 \%$ drop in survival of adult African penguins) when prey abundance decreases below a critical threshold level. Both the model and empirical analyses suggest that the critical (threshold) prey level varies depending on the life history characteristics of the species, as well as the interaction formulation. For example, penguins were predicted to be sensitive to sardine abundance, with a tipping point suggested at around $25 \%$ of the maximum observed level.

The impacts of ecosystem shifts go beyond the natural communities they affect, as they usually have marked social and economic effects. Understanding and mitigating the full suite of biological, economic and social impacts remains a challenge. The sustainable management of environmental resources requires striking a balance between ecological, economic and social values. Adaptive management approaches such as management strategy evaluation (MSE) (e.g. Smith et al. 1999, Plagányi et al. 2011) can be used to bring together ecological, economic and social values to adjust management appropriately towards pre-specified goals and in response to monitoring. Social-ecological governance systems typically cannot avoid abrupt shifts, and hence there is a need for robust governance systems with sufficient flexibility to buffer the worst impacts and conserve the social fabric of society (Duit \& Galaz 2008). MSE frameworks (Smith et al. 1999) can guide institutional and stakeholder responses when ecological thresholds are likely and hence enable more proactive planning.

Acknowledgements. This work was supported by the CSIRO Climate Adaptation and Wealth from Oceans Flagships. L.K.B. and W.R. gratefully acknowledge financial support from the University of Cape Town and the National Research Foundation. Data inputs provided by Marine and Coastal Management, South Africa and the Australian Institute of Marine Science Long-Term Monitoring Program and is gratefully acknowledged. Thanks go to A. Punt, R. Hillary, K. Hayes, R. Babcock and 2 anonymous reviewers for comments on earlier drafts.

\section{LITERATURE CITED}

Andersen T, Carstensen J, Hernández-García E, Duarte CM (2009) Ecological thresholds and regime shifts: approaches to identification. Trends Ecol Evol 24:49-57

Australian Government (2007) Commonwealth fisheries harvest strategy policy guidelines. Australian Government, Department of Agriculture, Fisheries and Forestry, Canberra

Bakun A, Weeks SJ (2006) Adverse feedback sequences in exploited marine systems: Are deliberate interruptive actions warranted? Fish Fish 7:316-333

> Bestelmeyer BT, Ellison AM, Fraser WR, Gorman KB and others (2011) Analysis of abrupt transitions in ecological systems. Ecosphere 2:art 129, doi:10.1890/ES11-00216.1

Blamey LK, Branch GM (2012) Regime shift of a kelp-forest benthic community induced by an 'invasion' of the rock lobster Jasus lalandii. J Exp Mar Biol Ecol 420-421: 33-47

> Blamey LK, Branch GM, Reaugh-Flower KE (2010) Temporal changes in kelp forest benthic communities following an invasion by the rock lobster Jasus lalandii. Afr J Mar Sci 32:481-490

Blamey LK, Howard JAE, Agenbag J, Jarre A (2012) Regime-shifts in the southern Benguela shelf and inshore region. Prog Oceanogr 106:80-95

> Blamey LK, Plagányi ÉE, Branch GM (2013) Modelling a regime shift in a kelp-forest ecosystem caused by a lobster range-expansion. Bull Mar Sci 89:347-375

> Blamey LK, Plagányi ÉE, Branch GM (2014) Was overfishing of predatory fish responsible for a lobster-induced regime shift in the Benguela? Ecol Model 273:140-150

> Boettiger C, Hastings A (2012) Early warning signals and the prosecutor's fallacy. Proc R Soc Ser B 279:4734-4739

> Boettiger C, Ross N, Hastings A (2013) Early warning signals: the charted and uncharted territories. Theor Ecol 6: $255-264$ 
Boyd IL, Croxall JP, Lunn NJ, Reid K (1995) Population demography of Antarctic fur seals - the costs of reproduction and implications for life-histories. J Anim Ecol 64:505-518

> Carpenter SR, Brock WA (2006) Rising variance: a leading indicator of ecological transition. Ecol Lett 9:311-318

Carpenter SR, Brock WA, Cole JJ, Kitchell JF, Pace ML (2008) Leading indicators of trophic cascades. Ecol Lett 11:128-138

Casini M, Hjelm J, Molinero JC, Lovgren J and others (2009) Trophic cascades promote threshold-like shifts in pelagic marine ecosystems. Proc Natl Acad Sci USA 106:197-202

Cleveland WS, Grosse E, Shyu WM (1992) Local regression models. In: Chambers JM, Hastie TJ (eds) Statistical models in S. Wadsworth \& Brooks/Cole, Pacific Grove, CA

> Cockcroft AC, van Zyl D, Hutchings L (2008) Large-scale changes in the spatial distribution of South African West Coast rock lobsters: an overview. Afr J Mar Sci 30: 149-159

Coetzee JC, van der Lingen CD, Hutchings L, Fairweather TP (2008) Has the fishery contributed to a major shift in the distribution of South African sardine? ICES J Mar Sci 65:1676-1688

> Crawford RJM, Barham PJ, Underhill LG, Shannon LJ and others (2006) The influence of food availability on breeding success of African penguins Spheniscus demersus at Robben Island, South Africa. Biol Conserv 132:119-125

Cury P, Boyd IL, Bonhommeau S, Anker-Nilssen T and others (2011) Global seabird response to forage fish depletion - one-third for the birds. Science 334:1703-1706

> Cury P, Bakun A, Crawford RJM, Jarre A, Quinones RA, Shannon LJ, Verheye HM (2000) Small pelagics in upwelling systems: patterns of interaction and structural changes in 'wasp-waist' ecosystems. ICES J Mar Sci 57: 603-618

> Dai L, Vorselen D, Korolev KS, Gore J (2012) Generic indicators for loss of resilience before a tipping point leading to population collapse. Science 336:1175-1177

> Day E, Branch GM (2000a) Evidence for a positive relationship between juvenile abalone Haliotis midae and the sea urchin Parechinus angulosus in the South-Western Cape, South Africa. S Afr J Mar Sci 22:145-156

Day E, Branch GM (2000b) Relationships between recruits of abalone Haliotis midae, encrusting corallines and the sea urchin Parechinus angulosus. S Afr J Mar Sci 22: 137-144

> de Moor CL, Butterworth DS, Coetzee JC (2008) Revised estimates of abundance of South African sardine and anchovy from acoustic surveys adjusting for echosounder saturation in earlier surveys and attenuation effects for sardine. Afr J Mar Sci 30:219-232

$>$ de Moor CL, Butterworth DS, De Oliveira JAA (2011) Is the management procedure approach equipped to handle short-lived pelagic species with their boom and bust dynamics? The case of the South African fishery for sardine and anchovy. ICES J Mar Sci 68:2075-2085

$>$ De'ath G, Moran PJ (1998) Factors affecting the behaviour of crown-of-thorns starfish (Acanthaster planci L.) on the Great Barrier Reef: 1. Patterns of activity. J Exp Mar Biol Ecol 220:83-106

> Drake JM, Griffen BD (2010) Early warning signals of extinction in deteriorating environments. Nature 467: 456-459

> Duit A, Galaz V (2008) Governance and complexity- emerging issues for governance theory. Governance 21: 311-335

Fabricius K, Okaji K, De'ath G (2010) Three lines of evidence to link outbreaks of the crown-of-thorns seastar Acanthaster planci to the release of larval food limitation. Coral Reefs 29:593-605

Folke C, Carpenter S, Walker B, Scheffer M, Elmqvist T, Gunderson L, Holling CS (2004) Regime shifts, resilience, and biodiversity in ecosystem management. Annu Rev Ecol Evol Syst 35:557-581

Fournier DA, Skaug HJ, Ancheta J, Ianelli JN and others (2012) AD Model Builder: using automatic differentiation for statistical inference of highly parameterized complex nonlinear models. Optim Methods Softw 27:233-249

> Groffman P, Baron J, Blett T, Gold A and others (2006) Ecological thresholds: the key to successful environmental management or an important concept with no practical application? Ecosystems 9:1-13

Holling CS (1973) Resilience and stability of ecological systems. Annu Rev Ecol Syst 4:1-23

Hughes TP (1994) Catastrophes, phase-shifts, and largescale degradation of a Caribbean coral reef. Science 265: 1547-1551

> Hughes TP, Rodrigues MJ, Bellwood DR, Ceccarelli D and others (2007) Phase shifts, herbivory, and the resilience of coral reefs to climate change. Curr Biol 17:360-365

- Lenton TM (2011) Early warning of climate tipping points. Nature Clim Change 1:201-209

Litzow MA, Mueter FJ, Urban JD (2013) Rising catch variability preceded historical fisheries collapses. Ecol Appl 23:1475-1487

Lynch HJ, Naveen R, Trathan PN, Fagan WF (2012) Spatially integrated assessment reveals widespread changes in penguin populations on the Antarctic Peninsula. Ecology 93:1367-1377

- May RM (1977) Thresholds and breakpoints in ecosystems with a multiplicity of stable states. Nature 269:471-477

> Mayfield S, Branch GM (2000) Interrelations among rock lobsters, sea urchins, and juvenile abalone: implications for community management. Can J Fish Aquat Sci 57: 2175-2185

McCook LJ (1999) Macroalgae, nutrients and phase shifts on coral reefs: scientific issues and management consequences for the Great Barrier Reef. Coral Reefs 18: 357-367

> Morello EE, Plagányi ÉE, Babcock R, Sweatman H, Hillary $\mathrm{R}$, Punt AE (2014) Modell to manage and reduce crownof-thorns starfish outbreaks. Mar Ecol Prog Ser 512: $167-183$

> Norstrom AV, Nystrom M, Lokrantz J, Folke C (2009) Alternative states on coral reefs: beyond coral-macroalgal phase shifts. Mar Ecol Prog Ser 376:295-306

Piatt JF, Methven DA (1992) Threshold foraging behaviour of baleen whales. Mar Ecol Prog Ser 84:205-210

> Plagányi ÉE (2013) Fitting the puzzle - modelling species interactions in marine ecosystems. Bull Mar Sci 89:397-417

> Plagányi ÉE, Butterworth DS (2010) A spatial- and agestructured assessment model to estimate the impact of illegal fishing and ecosystem change on the South African abalone Haliotis midae resource. Afr J Mar Sci 32:207-236

Plagányi ÉE, Butterworth DS (2012) The Scotia Sea krill fishery and its possible impacts on dependent predators: modeling localized depletion of prey. Ecol Appl 22: $748-761$ 
Plagányi ÉE, Weeks SJ, Skewes TD, Gibbs MT and others (2011) Assessing the adequacy of current fisheries management under changing climate: a southern synopsis. ICES J Mar Sci 68:1305-1317

Plagányi É, Punt A, Hillary R, Morello E and others (2014) Multi-species fisheries management and conservation: tactical applications using models of intermediate complexity. Fish Fish 15:1-22

Pratchett MS (2005) Dynamics of an outbreak population of Acanthaster planci at Lizard Island, northern Great Barrier Reef (1995-1999). Coral Reefs 24:453-462

Pratchett MS (2007) Feeding preferences of Acanthaster planci (Echinodermata: Asteroidea) under controlled conditions of food availability. Pac Sci 61:113-120

Pratchett MS (2010) Changes in coral assemblages during an outbreak of Acanthaster planci at Lizard Island, northern Great Barrier Reef (1995-1999). Coral Reefs 29: $717-725$

R Core Team (2013) R: a language and environment for statistical computing. R Foundation for Statistical Computing, Vienna. www.r-project.org

Robinson WML (2013) Modelling the impact of the South African small pelagic fishery on African penguin dynamics. PhD thesis, University of Cape Town

Rouault M, Penven P, Pohl B (2009) Warming in the Agulhas Current system since the 1980's. Geophys Res Lett 36: L12602, doi:10.1029/2009GL037987

Rouault M, Pohl B, Penven P (2010) Coastal oceanic climate change and variability from 1982 to 2009 around South Africa. Afr J Mar Sci 32:237-246

Roy C, van der Lingen CD, Coetzee JC, Lutjeharms JRE (2007) Abrupt environmental shift associated with changes in the distribution of Cape anchovy Engraulis encrasicolus spawners in the southern Benguela. Afr J Mar Sci 29:309-319

Scheffer M (1990) Multiplicity of stable states in freshwater systems. Hydrobiologia 200-201:475-486

Scheffer M, Carpenter SR (2003) Catastrophic regime shifts in ecosystems: linking theory to observation. Trends Ecol Evol 18:648-656

Submitted: November 11, 2013; Accepted: June 10, 2014
Scheffer M, Carpenter S, Foley JA, Folke C, Walker B (2001) Catastrophic shifts in ecosystems. Nature 413:591-596

Scheffer M, Bascompte J, Brock WA, Brovkin V and others (2009) Early-warning signals for critical transitions. Nature 461:53-59

Seymour RM, Bradbury RH (1992) Is the crown-of-thorns starfish degrading the Great Barrier Reef? J Theor Biol 159:111-133

Seymour RM, Bradbury RH (1999) Lengthening reef recovery times from crown-of-thorns outbreaks signal systemic degradation of the Great Barrier Reef. Mar Ecol Prog Ser 176:1-10

Smith ADM, Sainsbury KJ, Stevens RA (1999) Implementing effective fisheries-management systems - management strategy evaluation and the Australian partnership approach. ICES J Mar Sci 56:967-979

Sweatman H, Cheal A, Coleman G, Emslie M and others (2008) Long-term monitoring of the Great Barrier Reef. Status Report 8. Australian Institute of Marine Science, Townsville. www.aims.gov.au/docs/research/monitoring/ reef/status-reports.html

- Tarr RJQ, Williams PVG, Mackenzie AJ (1996) Abalone, sea urchins and rock lobster: a possible ecological shift that may affect traditional fisheries. S Afr J Mar Sci 17: 319-323

Underhill L, Crawford R, Wolfaardt A, Whittington P and others (2006) Regionally coherent trends in colonies of African penguins Spheniscus demersus in the Western Cape, South Africa, 1987-2005. Afr J Mar Sci 28: 697-704

Watters GM, Hill SL, Hinke JT, Matthews J, Reid K (2013) Decision-making for ecosystem-based management: evaluating options for a krill fishery with an ecosystem dynamics model. Ecol Appl 23:710-725

$>$ Wolf N, Mangel M (2008) Multiple hypothesis testing and the declining-population paradigm in Steller sea lions. Ecol Appl 18:1932-1955

$>$ Zann L, Brodie J, Vuki V (1990) History and dynamics of the crown-of-thorns starfish Acanthaster planci (L.) in the Suva area, Fiji. Coral Reefs 9:135-144

Proofs received from author(s): September 5, 2014 